\title{
Approximate solutions to problems in building thermal physics
}

\author{
Natalia Parfentyeva ${ }^{\mathrm{a}}$, Sabina Paulauskaite ${ }^{\mathrm{b}}$ \\ ${ }^{a}$ Moscow State Building University, Jaroslavskoye highway 26, Moscow 129337, Russia \\ ${ }^{b}$ Vilnius Gediminas Technical University, Sauletekio Ave 11, 10223 Vilnius, Lithuania
}

\begin{abstract}
Examples of approximate solutions to some building thermal physics problems, such as the definition of temperature, concentration and moisture fields, are presented. All the above problems require solving a heat equation in the presence of a heat transfer component and taking into account the parameters' dependence on the potential. To obtain the solutions, the Karman integral method, the comparison theorem and variational methods have been used. The obtaining of approximate solutions allows for the analysis of the dependence of time-dependent potentials on various parameters, and verification of the solutions obtained by numerical methods. Also, the benefits of and the need for obtaining approximate solutions in certain cases are shown. The effectiveness of approximation methods for solving complex equation systems and nonlinear problems is explained.
\end{abstract}

Keywords: approximate solutions, temperature, diffusion, nonlinear problems.

\section{Introduction}

Building thermal physics issues include the problems of determining temperature fields, moisture fields, as well as hydrodynamics and diffusion problems $[1,2]$.

Solving these problems generally comes down to solving the heat equation $[3,4]$, and therefore, the solutions obtained are universal and can be used in the analysis of various physical processes.

In fact, this is obvious since all the above processes are subject to one and the same fundamental pattern - the flux is proportional to the gradient of the scalar physical quantity which can be considered a potential. Time-dependent potentials include temperature T (Fourier's law), concentration n (Fick's law), elastic fluid pressure (Darcy's law) in an elastic medium $-\mathrm{p}$, moisture $\theta . \theta$ - is a moisture potential which is subject to similar fundamental patterns laws.

The basic physics to make the equation are the heat and material balance equations, i.e. energy and mass conservation

General form of the equation for $\varphi$-potential looks as follows [5, 6], Eqn (1):

$$
\frac{\partial \varphi}{\partial \mathrm{t}}=\mathrm{k} \Delta \varphi-\beta(\overrightarrow{\mathrm{v}} \vec{\nabla}) \varphi+\mathrm{q}(\overrightarrow{\mathrm{r}}, \mathrm{t})
$$

where $\varphi$ - nonstationary potential (temperature, concentration, etc.); $\mathrm{k}$ - transfer coefficient (thermal conductivity, diffusion, piezoconductivity, etc.); $\beta$ - coefficient, determining the ratio of macro- and microtransfer; $q$ - the source distributed over volume, for example, the number of particles per unit of time in a given point in space.The first term on the right-hand side of the equation takes into account the molecular component, and the second term - the convective component of transfer, $q(\vec{r}, t)$ - source distribution over volume.

To solve the equation, boundary and initial conditions are recorded according to the problem set.

With the advent of numerical solution methods [6,7] making it possible to model physical processes and solve Eqn (1) with complex boundary conditions present, in non-homogeneous media, in the event of phase changes, analytical solution methods have lost their former importance and are hardly ever used [8].

In our opinion, this situation is not quite fair.

Corresponding author: Sabina Paulauskaitė. E-mail address: sabina.paulauskaite@vgtu.lt

http://dx.doi.org/10.3846/enviro.2014.278

(C) 2014 The Authors. Published by VGTU Press. This is an open-access article distributed under the terms of the Creative Commons Attribution License, which permits unrestricted use, distribution, and reproduction in any medium, provided the original author and source are credited. 
It is indeed near-impossible to get an exact solution, but there are approximate solution methods that enable us to find simple formulas to make estimate calculations, analyze qualitative regularities and, most importantly, verify the solutions obtained by using numerical methods [7,9]. It is often required in solving nonlinear equations or problems, the mathematical model of which is a system of equations.

\section{Methodology}

Some relevant examples are given below.

1. Let us consider the problem of particles concentration distribution during the steady flow of liquid (air) along a flat plate with both molecular and convective mass transfer.

The complexity of solving this problem lies in the need to solve a system of Eqns (2):

$$
\begin{aligned}
& u_{x} \frac{\partial u_{x}}{\partial X}+u_{y} \frac{\partial u_{x}}{\partial Y}=\frac{1}{\operatorname{Re}} \frac{\partial^{2} u_{x}}{\partial Y^{2}} \\
& \frac{\partial u_{x}}{\partial X}+\frac{\partial u_{y}}{\partial Y}=0 \\
& u_{x} \frac{\partial n}{\partial X}+u_{y} \frac{\partial n}{\partial Y}=\frac{1}{\operatorname{Pe}} \frac{\partial^{2} n}{\partial Y^{2}}
\end{aligned}
$$

$\mathrm{u}$ - the velocity of fluid flowing along the plate, $\mathrm{n}$ - impurity concentration, Re, Pe - Reynolds and Peclet numbers respectively.

Let us solve this problem on an approximate basis using the Karman integral method [10].

Please note that this problem was solved in paper [9] using numerical methods.

Comparing the first and the third equations of the system (1), it can be concluded that in the particular case of the Reynolds and the Peclet numbers having the same value, the velocity and concentration distribution in the boundary layer will be the same; it is sufficient that the kinematic viscosity coefficient is equal to the diffusion coefficient.

The kinematic viscosity coefficient of air at the temperature of $20^{\circ} \mathrm{C}$ is on the order of $10^{-5} \mathrm{M}^{2} / \mathrm{c}$, the diffusion coefficient at the same temperature for particles of $1 \mu \mathrm{m}$ in diameter is on the order of $10^{-10} \mathrm{~m}^{2} / \mathrm{c}$. Therefore, assessing the thickness of boundary layers, it can be concluded, that they will be different in size. It should be noted that transfer coefficient values are determined with an accuracy not exceeding $10 \%$.

The Karman integral equation for the boundary layer obtained as per the laws of dynamics can be written as Eqn (3):

$$
\frac{d}{d x} \int_{0}^{h}\left(v_{\infty}-v_{x}\right) v_{x} d y=\tau_{x},
$$

where $\tau_{\mathrm{x}}$ is shear stress.

The approximate solution of this equation is obtained with boundary conditions, Eqns (4)

$$
\begin{aligned}
& \left.\mathrm{v}_{\mathrm{x}}\right|_{\mathrm{y}=0}=0,\left.\frac{\partial^{2} \mathrm{v}_{\mathrm{x}}}{\partial \mathrm{y}^{2}}\right|_{\mathrm{y}=0}=0, \\
& \left.\mathrm{v}_{\mathrm{x}}\right|_{\mathrm{y}=\delta}=\mathrm{v}_{\infty},\left.\frac{\partial \mathrm{v}_{\mathrm{x}}}{\partial \mathrm{y}}\right|_{\mathrm{y}=0}=0,
\end{aligned}
$$

$\delta$ - thickness of boundary layer.

Rendering the solution as a third-degree polynomial, the approximate solution is recorded as follows Eqn (5):

$$
\mathrm{v}_{\mathrm{x}}=\mathrm{v}_{0}\left(\frac{3}{2} \frac{\mathrm{y}}{\delta}-\frac{1}{2}\left(\frac{\mathrm{y}}{\delta}\right)^{3}\right) .
$$

For $\delta$ we have $-\delta(\mathrm{x})=\frac{4,64}{\sqrt{\frac{\mathrm{v}_{\infty} \mathrm{x}}{v}}}$.

Let us find a similar integral equation for the diffusion boundary layer assuming that the boundary layer has no additional sources, Eqn (6): 


$$
\frac{d}{d x} \int_{0}^{\delta_{\mu}}\left(n_{0}-n\right) v_{x} d y=-D\left(\frac{\partial n}{\partial y}\right)_{y=0} .
$$

To solve Eqn (4) let us establish the boundary conditions.

$$
\begin{gathered}
\mathrm{n}=0 \text { with } \mathrm{y}=0 \\
\mathrm{n}=\mathrm{n}_{0}, \frac{\partial \mathrm{n}}{\partial \mathrm{y}}=0 \quad \text { with } \mathrm{y} \rightarrow \infty .
\end{gathered}
$$

Based on the system (1), it can be written for concentration in our case, Eqn (7)

$$
\mathrm{v}_{\mathrm{x}} \frac{\partial \mathrm{n}}{\partial \mathrm{x}}+\mathrm{v}_{\mathrm{y}} \frac{\partial \mathrm{n}}{\partial \mathrm{y}}=\mathrm{D} \frac{\partial^{2} \mathrm{n}}{\partial \mathrm{y}^{2}}
$$

The boundary condition for the air-plate boundary takes the form of, Eqn (8):

$$
\left.\frac{\partial^{2} n}{\partial y^{2}}\right|_{y=0}=0 \text {. }
$$

Rendering the solution in the form of a third-degree polynomial, we get, Eqn (9)

$$
\frac{\mathrm{n}}{\mathrm{n}_{0}}=\frac{3}{2}\left(\frac{\mathrm{y}}{\delta_{\mathrm{d}}}\right)-\frac{1}{2}\left(\frac{\mathrm{y}}{\delta_{\mathrm{d}}}\right)^{3}
$$

The thickness of the diffusion boundary layer is determined by the Eqn (10):

$$
\delta_{\mathrm{d}}=\frac{\delta}{\sqrt[3]{\mathrm{Pr}^{\prime}}}=\frac{1}{\sqrt[3]{\mathrm{Pr}^{\prime}}} 4,64 \sqrt{\frac{v \mathrm{x}}{\mathrm{v}_{0}}} .
$$

For this purpose, we have taken into account by comparing the transfer coefficients that the diffusion boundary layer is thinner than the hydrodynamic boundary layer.

Then, Eqn (9) takes the form of Eqn (11):

$$
\frac{3}{20} \mathrm{n}_{0} \mathrm{v}_{0} \frac{\mathrm{d}}{\mathrm{dx}}\left(\frac{\delta^{2} \mathrm{~d}}{\delta}\right)=\frac{3}{2} \mathrm{D} \frac{\mathrm{n}_{0}}{\delta_{\mathrm{d}}} .
$$

Denoting the relation of the diffusion layer thickness to that of the hydrodynamic boundary layer by letter $\mathrm{k}=\frac{\delta_{\mathrm{d}}}{\delta}$, we get Eqn (12)

$$
\mathrm{k}^{3} \delta \frac{\mathrm{d} \delta}{\mathrm{dx}}+2 \mathrm{k}^{2} \delta^{2} \frac{\mathrm{dk}}{\mathrm{dx}}=10 \frac{\mathrm{D}}{\mathrm{v}_{0}}
$$

The expression for $\delta$ known from the solution of the Karman integral equation for the boundary layer. As a result of integration of the equation written, we get the expression for $\mathrm{k}$ coefficient, Eqn (13).

$$
\mathrm{k}=\sqrt[3]{\frac{\mathrm{D}}{v}} .
$$

If we introduce a non-dimensional parameter similar to the Prandtl number, we have Eqn (14)

$$
\frac{\delta_{\mathrm{d}}}{\delta}=\frac{1}{\sqrt[3]{\operatorname{Pr}^{\prime}}} .
$$

The diffusion coefficient is lower than the kinematic viscosity coefficient, which implies that the diffusion boundary layer is thinner than the hydrodynamic boundary layer.

The thickness of the diffusion boundary layer is defined by the following expression, Eqn (15) 


$$
\delta_{\mathrm{d}}=\frac{\delta}{\sqrt[3]{\mathrm{Pr}^{\prime}}}=\frac{1}{\sqrt[3]{\operatorname{Pr}^{\prime}}} 4,64 \sqrt{\frac{v \mathrm{x}}{\mathrm{v}_{0}}} .
$$

By inserting this expression into (15), we get the concentration of airborne particles along the vertical axis.

This solution allows us estimate the concentration field.

2. Given below is an example of the use of a different approximation method for solving a nonlinear equation.

The nonlinearity of the equation comes about when the dependence of transfer coefficients from the nonstationary potential has to be taken into account. It happens in case of a very large range in potential change such as temperature change within an enclosure in the event of fire, or change in the material moisture content in the event of an abrupt change in temperature, Eqn (16).

$$
\frac{\partial \varphi}{\partial \mathrm{t}}=\frac{\partial}{\partial \mathrm{x}}\left[\mathrm{k}(\varphi) \frac{\partial \varphi}{\partial \mathrm{x}}\right],
$$

where $\varphi$ is a non-dimensional value (potential), determined by the relation of the potential to its value at the border [8], Eqn (17):

$$
\begin{gathered}
\varphi=\frac{T}{T_{c}}\left(\frac{p}{p_{c}}, \frac{n}{n_{c}}\right) . \\
\varphi_{x=0}=1,\left.\varphi\right|_{t=0}=\left.\varphi\right|_{x \rightarrow \infty}=0 .
\end{gathered}
$$

The principle of obtaining the solution comes down to transforming the equation so that its variable part is removed from the derivative sign and becomes a variable coefficient.

1) Let us consider as the first dependence Eqn (18):

$$
\mathrm{k}(\varphi)=\frac{\mathrm{k}_{0}}{1-\alpha \varphi} .
$$

Let us proceed to the new unknown function $\Psi=\ln (1-\alpha \varphi)$.

Then, Eqn (1) is transformed as follows Eqn (19):

$$
\frac{\mathrm{k}_{0}}{\mathrm{e}^{\Psi}} \frac{\partial^{2} \Psi}{\partial \mathrm{x}^{2}}=\frac{\partial \Psi}{\partial \mathrm{t}},
$$

and is solved with the following conditions Eqn (20):

$$
\begin{gathered}
\left.\Psi\right|_{\mathrm{x}=0}=\ln (1-\alpha)=\mathrm{A}<0, \\
\left.\Psi\right|_{\mathrm{t}=0}=\Psi_{\mathrm{x} \rightarrow \infty}=0 . \\
\mathrm{A}<\Psi<0 .
\end{gathered}
$$

By inserting into Eqn (19) coefficient maximum and minimum equations, we get two equations (21):

$$
\begin{aligned}
& \mathrm{k}_{1} \frac{\partial^{2} \mathrm{u}_{1}}{\partial \mathrm{x}^{2}}=\frac{\partial \mathrm{u}_{1}}{\partial \mathrm{t}} \\
& \mathrm{k}_{2} \frac{\partial^{2} \mathrm{u}_{2}}{\partial \mathrm{x}^{2}}=\frac{\partial \mathrm{u}_{2}}{\partial \mathrm{t}}
\end{aligned}
$$

with the same boundary and initial conditions, Eqns (22):

$$
\begin{aligned}
& \left.\mathrm{u}_{1}\right|_{\mathrm{x}=0}=\left.\mathrm{u}_{2}\right|_{\mathrm{x}=0}=\mathrm{C}_{1} \\
& \left.\mathrm{u}_{1}\right|_{\mathrm{x} \rightarrow \infty}=\left.\mathrm{u}_{2}\right|_{\mathrm{x} \rightarrow \infty}=\left.\mathrm{u}_{1}\right|_{\mathrm{t}=0}=\left.\mathrm{u}_{2}\right|_{\mathrm{t}=0}=\mathrm{C}_{2}
\end{aligned}
$$

If $\mathrm{k}_{2}>\mathrm{k}_{1}$ and $\mathrm{C}_{2}>\mathrm{C}_{1}$, the $\mathrm{u}_{1}$ - coordinate curve will be above the $\mathrm{u}_{2}(\mathrm{x})$ dependence curve at any given time.

The solution of equations (21) take the form of Eqns (23): 


$$
\begin{aligned}
& \mathrm{u}_{1}=\ln (1-\alpha)(1-\operatorname{erf} \sqrt{1-\alpha} \xi) \\
& \mathrm{u}_{2}=\ln (1-\alpha)(1-\operatorname{erf} \xi),
\end{aligned}
$$

where $\xi=\frac{\mathrm{x}}{2 \sqrt{\mathrm{k}_{0} \mathrm{t}}}$.

Calculations show that in many cases dependence curves Eqn (24):

$$
\mathrm{u}_{\text {пр }}(\mathrm{x}, \mathrm{t})=\frac{\mathrm{u}_{1}(\mathrm{x}, \mathrm{t})+\mathrm{u}_{2}(\mathrm{x}, \mathrm{t})}{2}
$$

or Eqn (25):

$$
u_{\text {пр }}(x, t)=\sqrt{u_{1}(x, t) \cdot u_{2}(x, t)} .
$$

The solution in this case is shown on Fig. 1.

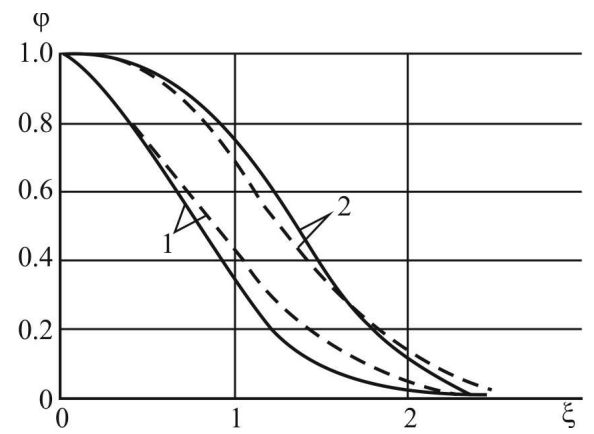

Fig. 1. Dependences $\varphi(\xi)$ in case of the dependence $\mathrm{k}(\varphi)=\frac{\mathrm{k}_{0}}{1-\alpha \varphi}$, obtained using approximation (dashed line) and numerical methods. Curves $1-\alpha=0,8$; curves $2-\alpha=0,98$.

2) The transfer parameter dependence most frequently occurring in practice Eqn (26):

$$
\mathrm{k}(\Phi)=\mathrm{k}_{0}(1+\alpha \varphi) \text {. }
$$

Let us replace $\Psi=(1+\alpha \varphi)^{2}$.

Then, with respect to $\Psi$, we have the Eqn (27):

$$
\mathrm{k}_{0} \sqrt{\Psi} \frac{\partial^{2} \Psi}{\partial \mathrm{x}^{2}}=\frac{\partial \Psi}{\partial \mathrm{t}}
$$

under the following conditions, Eqns (28):

$$
\begin{gathered}
\left.\Psi\right|_{\mathrm{x}=0}=(1+\alpha)^{2}, \\
\left.\Psi\right|_{\mathrm{t}=0}=\left.\Psi\right|_{\mathrm{x} \rightarrow \infty}=1 . \\
\mathrm{u}_{\text {пр }}(\mathrm{x}, \mathrm{t})=\frac{\mathrm{u}_{1}(\mathrm{x}, \mathrm{t})+\mathrm{u}_{2}(\mathrm{x}, \mathrm{t})}{2} .
\end{gathered}
$$

The solution of the equation using a variational method, for instance, the Bubnov-Galerkin method [2] takes the form of Eqn (29):

$$
\Psi(\xi)=\left(1-\frac{1}{2 \sqrt{10 \mathrm{M} \xi}}\right)
$$

where $M=\frac{1}{3}-\frac{3}{5} \alpha$. 
The comparison of analytical and approximate solutions has shown that the approximate solution method gives fairly good results, as the approximate solution error did not exceed $5 \%$.

The comparison of exact and approximate solutions obtained using the Bubnov-Galerkin method, has shown that the both methods give essentially very close solution results except for small time values

3) Let us take the dependence Eqn (30):

$$
\mathrm{k}(\varphi)=\frac{\mathrm{k}_{0}}{(1-\alpha \varphi)^{2}}
$$

After the replacement of $\Psi=\frac{1}{1-\alpha \varphi}$, we come to the Eqns (31):

$$
\begin{aligned}
& \mathrm{k}_{0} \Psi^{2} \frac{\partial^{2} \Psi}{\partial \mathrm{x}^{2}}=\frac{\partial \Psi}{\partial \mathrm{t}}, \\
& \left.\Psi\right|_{\mathrm{x}=0}=\frac{1}{1-\alpha} \\
& \left.\Psi\right|_{\mathrm{x} \rightarrow \infty}=\left.\Psi\right|_{\mathrm{t}=0}=1
\end{aligned}
$$

The solution in this case is shown on Fig. 2.

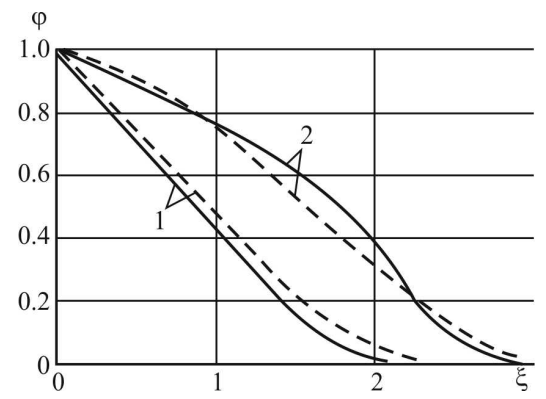

Fig. 2. Dependences $\varphi(\xi)$ in case of the dependence $\mathrm{k}(\varphi)=\frac{\mathrm{k}_{0}}{(1-\alpha \varphi)^{2}}$, obtained using approximation (dashed line) and numerical methods.

Curves $1-\alpha=0,553$; curves $2-\alpha=0,86$.

In these examples, exact solutions to linear equations can be obtained. However, in more complex cases two approximation methods have to be used; firstly, a nonlinear equation gets linearized, and, secondly, the equations are solved using one of the approximation methods. However, calculations show that such an approach to problem solving is rather efficient.

The approximation methods have also proven their efficiency in solving problems with phase changes [3, 11].

\section{Results}

These examples show the efficiency of using approximate solution methods in solving building thermal physics problems. A similar method has been previously applied by the authors to solve specific heat exchanger calculation problems, and problems involving phase changes. [9, 10]. It may safely be said that approximation method often allow us not only to analyse the accuracy of a solution obtained by numerical methods, but also to use the solution for engineering calculations. It should be kept in mind that the accuracy of the parameters used in calculations is generally lower than the accuracy of the approximate solution. It should be noted that in more complex cases two approximation methods have to be used; firstly, a nonlinear equation gets linearized, and, secondly, the equations are solved using one of the approximation methods.

\section{Conclusions}

Finding the way to define nonstationary potentials is one of the main problems in building thermal physics. Formulas need to be in place for the calculation of thermal heat losses, moisture fields, etc.

To solve such problems, the authors propose using approximate methods which enable us to obtain fairly simple solutions and perform the physical analysis of the processes taking place. 


\section{References}

[1] Богословский, В. Н. 1982. Строительнаятеплофизика. Москва.Высшаяшкола, 415 c. (BogoslovskyV.N.1982.Building Thermal Physics . Moscow, Vysshaya Shkola Publishing House, 415).

[2] Шервуд, Т.; Пигфорд, Р.; Уилки, Ч. 1982. Macconepeдача. Москва. (Sherwood T., Pigford R., and Wilkie C.,1982. Mass Transfer. Moscow).

[3] Парфентьева, Н. А.; Самарин, О. Д. 2005. Об экспериментальном подтверждении решения задачи Стефана.Мозсош. Кровля и изоляция, №3, 51-52 (Parfentyeva N.A., Samarin O.D. 2005.On Experimental Validation of the Stefan Problem Solution. Moscow. Roofing and Insulation, No. 3, 51-52).

[4] Фридман, А. 1998. Уравнения с частными производными параболического типа. Москва. Издательство «Мир», (Friedman А., 1998.Parabolic-type Partial Differential Equations, Moscow, Mir Publishing House).

[5] Maurits, W. ;Vandegehuchte, K. S. 2012. Use of the correct heat conduction - convection equation asbasis for heat-pulse sap flow methods in anisotropic case, Journal of Experimental Botany 63(8): 2833-2839. http://dx.doi.org/10.1093/jxb/ers041

[6] Прусаков, Г. М. 1993. Математические модели и методы в расчетах на ЭВМ. Москва. Издательство Наука, 144 с. (Рrusakov G.M., 1993. Mathematical Models and Methods in ECM Calculations. Moscow. Nauka Publishing House, 144-150).

[7] Пименов, В. Г. 2008. Численные методы решения уравнения теплопроводности. Вестник Удмурдского Университета. Вып. 2, математика. (Pimenov V.G., 2008. Numerical Methods for Solving Heat Equations. Bulletin of the University of Udmurtia . Issue 2, Mathematics).

[8] Higgins, B. G. 2009. Temperature-Dependent Thermal Conductivity.Department of Chemical Engineering \& Materials ScienceUniversity of California, Davis [online]. Available from Internet: http://www.ekayasolutions.com/UCDMath/TempDependCond.pdf.

[9] Самарский, А. А.; Вабищевич, П. Н. 1999. Численные методы решения задач конвекции-диффузии. Москва. Эдиториал УРСС, 248 (Samarsky A.A, Vabishchevich P.N., 1999. Numerical Methods for Solving Convection-Diffusion Problems. Moscow. Editorial URSS, 1999, 248).

[10] Амромин, Э. Л.; Бушковский, В. А. 1997. Вариационный подход к трехмерным задачам теории потенциала. Москва. Журнал технической физики, m. 67, № 7, 12-14.(Amromin E., Bushkovsky V. Variational approach to three-dimensional problems of potential theory. Moscow. Journal of Technical Physics, Vol 67).

[11] Парфентьева, Н. А.; Самарин, О. Д. 2007. Решение задачи Стефана при промерзании трубопроводов. Москва. Вестник МГСУ, № 1, 67-70. (Parfentyeva N.A., Samarin O.D. 2007. The Solution of the Stefan Problem Arising in Freezing Pipelines. Moscow. Moscow State Construction University Bulletin 2007, No. 1, 67-70). 